\section{REVISTA}

Actualidades Investigativas en Educación http://revista.inie.ucr.ac.cr/

ISSN 1409-4703

\title{
INTERACTIONS 1 AS AN ELT COURSEBOOK: A CURRICULAR AND THEORY-BASED SCRUTINY
}

INTERACTIONS 1 COMO LIBRO DE TEXTO PARA LA ENSEÑANZA DEL INGLÉS: UN ANÁLISIS TEÓRICO-CURRICULAR

\section{Volumen 15, Número 3}

Setiembre - Diciembre

pp.1-36

\section{Este número se publicó el $1^{\circ}$ de setiembre de 2015 \\ DOI: http://dx.doi.org/10.15517/aie.v15i3.20982}

\author{
Henry Sevilla Morales \\ Roy Gamboa Mena
}

Revista indizada en REDALYC, $\underline{\text { SCIELO }}$

Revista distribuida en las bases de datos:

CATÁLOGO DE LATINDEX, IRESIE, CLASE, DIALNET, DOAJ, E-REVIST@S, SHERPA/ROMEO, QUALIS, MIAR

Revista registrada en los directorios:

ULRICH'S, $\underline{\text { REDIE}}, \underline{\text { RINACE}}, \underline{\text { OEI }}$ MAESTROTECA, PREAL, $\underline{\text { CLACSO }}$ 


\title{
INTERACTIONS 1 AS AN ELT COURSEBOOK: A CURRICULAR AND THEORY-BASED SCRUTINY \\ INTERACTIONS 1 COMO LIBRO DE TEXTO PARA LA ENSEÑANZA DEL INGLÉS: UN ANÁLISIS TEÓRICO-CURRICULAR
}

\author{
Henry Sevilla Morales ${ }^{1}$ \\ Roy Gamboa Mena ${ }^{2}$
}

\begin{abstract}
This article analyzes the pertinence of Interactions 1 as the core textbook in the 10-5400 Oral Communication I course, a first-year-course of the Bachelor's Program in English Teaching at a public university in Costa Rica. Thus, the methodology proposed in the textbook, its design (images, teaching strategies for the development of oral and listening skills, supplementary book resources, among others) and its curricular approach were studied in order to determine the congruence between the theoretical principles established by the experts on materials design and evaluation and the book in question. Along the same lines, the pertinence of the book in relation to different aspects of the curriculum of the major, such as the students' exit profile, the objectives and the methodology, among others, were also analyzed. This is a descriptive study that undertook mixed research strategies, where data collection instruments such as a checklist and a Likert scale were combined; the data analysis and interpretation was done through triangulation. The study revealed, on the one hand, that the level of congruence of Interactions 1 with the theoretical principles of materials design and evaluation is insufficient. Conversely, with regard to the curricular aspects of the major, the book proved acceptable as long as instructors contextualize and supplement it with their own resources and teaching strategies so that it is fully satisfactory to the English learning process. Findings call for the use of research-informed criteria in ELT materials design which match the specific English teaching language curricula.
\end{abstract}

Key words: ELT MATERIALS DESIGN, ELT MATERIALS EVALUATION, ENGLISH TEACHING, HIGHER EDUCATION, COSTA RICA

Resumen: El presente artículo analiza la pertinencia del libro Interactions 1 como texto utilizado en el curso IO5400 Comunicación Oral l, perteneciente al primer año de la carrera de Bachillerato en la Enseñanza del inglés en una universidad pública en Costa Rica. En este sentido, se estudia la metodología propuesta en el texto, su diseño (imágenes, estrategias didácticas para el desarrollo de habilidades orales y auditivas, recursos que acompañan el texto, entre otros) y su enfoque curricular, a fin de determinar la congruencia entre los principios teóricos que establecen los autores acerca de la evaluación y el diseño de los recursos didácticos y el texto supra citado. Asimismo, se analizó la pertinencia de dicho texto con diferentes aspectos que contiene el currículo de la carrera como: el perfil de salida del estudiante, los objetivos y la metodología, entre otros. El estudio se basó en una metodología de investigación descriptiva donde se combinan estrategias para la recolección de la información, tales como listas de cotejo y escalas Likert. El análisis e interpretación de los datos se realizó mediante la triangulación de fuentes. El estudio devela, por una parte, que el nivel de coherencia del texto Interactions 1 con los principios teóricos para el diseño y la evaluación de recursos didácticos, es insuficiente con respecto a los criterios especializados para esta área. Por otra parte, en relación con los aspectos del currículo de la carrera, resulta aceptable en tanto el docente debe contextualizarlo y complementarlo con sus propios recursos y estrategias didácticas para que resulte totalmente satisfactorio al proceso de aprendizaje del idioma Inglés. El aporte fundamental del estudio comprueba la necesidad de utilizar criterios técnicos para el diseño de recursos didácticos afines al enfoque curricular de los planes de estudios de Enseñanza del Inglés.

Palabras clave: DISEÑO DE RECURSOS DIDÁCTICOS, EVALUACIÓN DE RECURSOS DIDÁCTICOS, ENSEÑANZA DEL INGLÉS, EDUCACIÓN SUPERIOR, COSTA RICA

\footnotetext{
${ }^{1}$ Profesor de la Carrera de Bachillerato y Licenciatura en la Enseñanza del Inglés de la Universidad de Costa Rica, Sede de Occidente. Máster en Segundas Lenguas y Culturas. Dirección electrónica: al deron@hotmail.com

${ }^{2}$ Profesor de la Carrera de Bachillerato y Licenciatura en la Enseñanza del Inglés de la Universidad de Costa Rica, Sede de Occidente. Magíster en la Enseñanza del Inglés como Lengua Extranjera. Dirección electrónica: roy.gamboa@ucr.ac.cr
}

Artículo recibido: 2 de octubre, 2014

Enviado a corrección: 26 de febrero, 2015

Aprobado: 17 de agosto, 2015 


\section{Introduction}

Recent advancements in the field of applied linguistics have stressed the central role materials occupy in the area of second and foreign language teaching. Authorities in the field such as McGrath (2002), McDonough and Shaw (2003), Tomlinson (2003), and Harwood (2010) have helped vindicate this role by calling for renewed and research-informed decisions in the selection, implementation and evaluation of English Language Teaching materials (henceforth, ELT) both in EFL and ESL. Henceforth, a number of empirical studies (e.g., Gray, 2000; Sahragard, Rahimi, and Zaremoayeddy, 2008; Johnson et al., 2008; Tuan, 2012; Gómez, 2012, and many others) have been conducted, all of them aiming at elucidating the emerging issues and dilemmas around this field of study. In spite of these advancements, experts are still debating over several issues such as practicality, appropriacy, and usefulness of ELT materials.

In the particular case of usefulness, the divergent views between those who see materials as important resources to the teaching-learning endeavor on the one hand, and those who view them just as "skillfully marketed' 'masses of rubbish" on the other (Brumfit, 1980, p., 30, in Tomlinson, 2003, p. 40), have led others to grow skeptical about the contribution of textbooks to language learning because, as Cunningsworth (1984) warns, they "are good servants but bad masters" (in Tomlinson, 2003, p. 40). This opposition has raised questions as to how to adapt language that is often not-real-life-like in textbooks into more natural and real-life-like samples of language usage; or how to provide sufficient materials so that a big majority of learners can benefit from them, while at the same time keep them flexible for adaptation and use; or, most critically, how coursebooks can foster an interactive and dynamic learning process while at the same time keep consistency with the course syllabus proposed by the institution (Gower, 1998, p. 117, in Tomlinson, 2003, p. 40).

While the debate between these two positions might not come to an end soon, the authors of the present paper take on the position that although a coursebook might not make a significant learning difference by its own (as acknowledged by McDonough and Shaw, 2003 , p. 61), they certainly offer a valuable resource to assist the language teaching and learning process. Ergo, the present paper takes a stand in evaluating the degree of pertinence and compliance of the book Interactions 1 with principles of ELT materials development, as well as in determining the degree of consistency between coursebook and curriculum of the institution where the study was conducted. 
To this end, the researchers have resolved to answer the question: How suitable is the book Interactions 1 as the core textbook in a first-year oral communication course in a public university of Costa Rica? In an attempt to answer this question, the researchers set forth to: a) Scrutinize the methodological makeup of the book in mention for congruence with theory on materials development and evaluation and b) examine the congruence of the textbook with the English Teaching Major's curriculum of the institution. Combining qualitative and quantitative research methods and strategies, the researchers undertook a curricular and theory-based analysis of the textbook that used both researcher's empirical knowledge and current principles of ELT materials design and evaluation as the foundations for the analysis. The authors based the analysis of the first research objective on a theoretical framework devised from current theory on ELT materials development; the attainment of the second objective, alternatively, was conducted by scrutinizing the institution's curriculum in terms of congruence with the textbook under analysis.

The textbook Interactions 1 written by Linda Baker, Pamela Hartmann, Darcy Jack, Elaine Kirn, Paul Most, Jill Korey O'Sullivan, Cheryll Pavlik, Margaret Keenan Segal, and Judith Tanka and published by McGraw Hill in 2003, has been used in the major in question for more than one decade and, to date, no changes in edition have been adopted; and no formal evaluations of the book have been conducted either at the branch or in Costa Rica. Thus, the present study is significant because it pioneers an analysis that touches upon both principles of materials development and the curricular foundations this major rests upon. The findings may help curricular authorities and stakeholders make research-informed decisions about implementation, adaption, or replacement of this or similar coursebooks, as they also assist our understanding of ELT materials development and evaluation at large. A last implication of this research is that it enlarges the amount of available literature in a research area of applied linguistics that has proven neglected in Costa Rica and in many other countries where English language teaching and learning is a central part of the education agenda.

\section{Literature Review}

For the purpose of clarity, the researchers have organized this section into three main subsections: A framework for ELT materials development and evaluation, an overview of the ETM curriculum of the major, and a review of recent studies in the field of ELT materials development and evaluation. 


\subsection{A Framework for ELT Materials Development and Evaluation}

As stated elsewhere in this paper, recent developments in ELT over the past few decades have led language experts to a renewed interest in the role materials play in ESL and EFL instruction. With materials evaluation, specifically, defining the criteria to use before, during, and after choosing a textbook has been one of the top priorities in the pedagogical agendas of language professionals; however, the answers as to the best ways to conduct ETL materials evaluation are still to be sought. In an attempt to help elucidate this issue, the authors of this paper have drawn on the works of recent authorities in the field such as Tomlinson (2003), McGrath (2002), McDonough and Shaw (2003), and Harwood (2010) to devise a framework for the evaluation of the book at stake that can potentially serve not only as decision making for the immediate selection of ELT coursebooks, but also as a framework for the development and evaluation of future ELT materials.

Thus, the first category we have devised for our framework is the author and the publishing house. Among the many criteria that can be taken into account in materials evaluation regarding this category, Tomlinson (2003) suggests the following: ensuring that the author is a reputable authority in the field of language teaching-learning, verifying whether $\mathrm{s}$ /he has published other ELT materials, checking that $\mathrm{s}$ /he has enough teaching and educational research experience, and corroborating that $s /$ he is affiliated to a renowned university or language teaching institution. About the publishing house, Tomlinson (2003) suggests that one make sure it is well-known, that it has a good publishing record, and that it has representatives in the country where the books are purchased.

Following the author and the publishing house is the cost of a coursebook. Though it might seem commonsense, choosing affordable materials is not always the norm in many EFL/ESL institutions. McGrath (2002) advices that one must consider not only the cost of the coursebook but also the cost of supplementary materials that come with it (p. 24). She also advices weighing practical considerations that deal with the cost, such as durability and size of the student's book (McGrath, 2002, p. 51).

The third category is the layout. As it has been agreed by experts, the layout cannot be selected haphazardly. Materials assessors need to make sure that features like the color of the pages, cover design, content distribution, and graphs and images, match the population for which the book has been chosen. Authorities warn that, as discussed by McDonough and Shaw (2003), any visuals must serve a leaning purpose rather than just a "cosmetic value" (p. 65). This is part of an evaluation stage which McGrath calls first glance evaluation, through 
which we can also confirm or disconfirm congruence between coursebook and the learning context and the needs of the students (p. 29).

The next category in our framework is the setting. Defining criteria to use in determining the suitability of ELT materials in terms of the setting is by far one of the most crucial stages of materials evaluation. The trick lies on the fact that too many criteria have been devised on this rather than on the scarcity of it. In order to attend to this controversy, we have identified the following as the core criteria to pay attention to when evaluating the setting: Making sure the textbook matches the role of the target language in the country (i.e., whether EFL ESL, or ESP), ensuring it matches the role of the target language as conceived in the school and the overall language curriculum, and corroborating that it matches up with the students' sociocultural realities and consistently allows for the use of its additional components (online resources, for instance), within the teaching resources available in the institution. In addition to that, evaluators need to confirm that the book is in harmony with the curriculum in terms of its duration, and that it is adjustable to the physical environment of the institution -i.e., class size, noise levels, etc. - (Tomlinson, 2003).

Along with the setting, the syllabus and the objectives comprise a crucial category in materials assessment. Once matching between all of the elements in the setting has been verified, Tomlinson (2003) claims, a closer scrutiny to cross-check congruence between syllabus objectives and those proposed in the textbook, achievability of tasks in terms of time frame and proposed learning context, syllabus orientation towards achieving communicative competencies, and many others must be carried out. Criteria to evaluate in this category include the communicatibility of the book, congruence between coursebook objectives and those proposed in the book, achievability of learning objectives, and whether the syllabus is grounded in learning-centered principles. If this congruence is not verified, the selection of the material must be rethought and reoriented.

The next category is the target audience. McDonough and Shaw argue that materials must be targeted to the audience for which they were designed not only in terms of age, but also in terms of their proficiency level, especially because proficiency levels tend to vary significantly depending on the educational context (2003, p. 63). McGrath (2002), along the same lines, claims that coursebooks must meet, among many others, some minimal criteria. For instance, they must match the learners in terms of needs and interests, they need to have been created for the context they are addressed (i.e., whether ESL or EFL), they must-as previously argued by McDonough and Shaw - match the students' proficiency level and 
ages, they must be consistent with the learners' aptitudes in terms of main talents and skills, and they must, finally, match the students' reasons for learning a language.

A very ample yet crucial category in this framework deals with methodological considerations from the angles of both learning and teaching principles. According to Tomlinson (2003), in terms of learning, the assessor's learning theory plays a greater role than they generally realize. They must be aware of the latest-and, naturally, the bestresearch findings on language learning theory. Tomlinson (2003) points out that effective, durable learning requires "deep processing of intake" on the part of the learner, which is often related to their levels of affective engagement (19). Effective learning, as he goes on to argue, requires making connections not only between the new material and the students' background knowledge, but also with the potential value of learning in their future life, so there is need for both "instrumental and integral motivation" in effective learning that assessors need to bear in mind. Students will be more likely to learn "if they need and want to learn and if they are willing to invest time and energy" in it (Dörnyei and otto, 1998, in Tomlinson, 2003, p. 19). Besides these principles, materials must be developed within an approach that allows the learner to transact with the learning experience through "emotions, attitudes, opinions and ideas" (Jacobs and Schumann, in Tomlinson, 2003, p. 20) because, as previously stated by Berman (1999, p. 2), "we learn best when we see things as part of a recognized pattern, when our imaginations are aroused" (in Tomlinson, 2003, p. 20).

From the viewpoint of teaching principles, in his article Second language acquisition research and language-teaching materials, Rod Ellis (2010) discusses a number of elements that are pertinent to the teaching theory and that must be taken into consideration when evaluating and selecting coursebooks. The author asserts that materials assessors must keep in mind whether-and to what extent- the textbook has been grounded in CLT approaches, whether the exercises are focused on meaning rather than on form, and whether the book offers a series of tasks, both focused and unfocused, as well as contextualized grammar exercises. Along the same lines, it is important-he goes on to argue-that the tasks be arranged in a way that they foster meaningful connections with the students' personal experiences, and that the book's teaching philosophy allow for both task-based and task-supported language teaching (in Harwood, 2010).

Adding up to the framework for materials evaluation are the general and specific instructions. Simple as it may appear, instructions are an aspect of materials evaluation that tends to be overlooked by most textbook evaluators. In their books, Selection of Materials and 
A Practical Guide to Assessing English Language Learners, respectively, Tomlinson (2003) and Coombe, Folse, and Hubley (2007) offer an insight on the main criteria to follow when assessing this category. Both authors agree that instructions must be succinct, and they need to provide enough guidance onto what learners are expected to do. They need to be selfstanding, and they need to be separated using numbers or bullets to facilitate comprehension. They also need to be written sequentially according to what the students have to do, and they must focus on what they must, rather on what they must not do. Lastly, and most importantly, they need to be written in a clear and grammatically correct form.

The role of grammar comprises the next category of this framework. While we know that, traditionally, grammar has been taught deductively (i.e., in a rule-driven manner), contemporary authors like Ellis (2010) have taken a stand in proposing that grammar needs to take more discovery-driven routes where learners have the opportunity to: learn grammar through input processing rather than by eliciting the production of structures in isolation, make use of different types of activities such as "interpretation activities", "input enrichment activities", "structured input activities", and "consciousness-raising activities" (pp. 44-50). All of this, the author suggests, must be taught within a contextualized framework that responds and caters to the students' needs and reasons for learning a second or foreign language. While the list of principles regarding the role grammar should play in ELT coursebooks is by no means extensive, this paper will center around the ones herein discussed.

The next category in the framework is the teaching of listening. Along with the argument made by Vandergrift (1999, cited in McDonough and Shaw, 2003, p. 121) that listening is a very active skill where transactions occur between the message and the listener, McDonough and Shaw have claimed that effective listening comprehension takes place when a number of considerations of process and product are held in mind, and that sensitive ELT materials should combine different activities that cater to the listening competencies we seek to develop in students; all of this, as the authors go on to state, brought together in the form of "pre, while, and post-listening activities (pp. 127-129).

Together with the teaching of listening, the teaching of speaking is a crucial element in our framework. Dat (2003) has proposed that, given the complexity and evolving methodological trends in the teaching and learning of speaking, ELT materials need to be developed using a five-dimension framework: "(1) conceptualizing learner needs; (2) identifying subject matter and communication situations; (3) identifying verbal communication strategies; (4) utilizing verbal source from real life; and (5) designing skill-acquiring activities" 
(pp. 381-384). Along the same lines, the author goes on to propose that aspects such as "the need for reflection on learner identity [...and] the need for cultural localization of materials" are also aspects that deserve attention in the development, selection and appraisal of classroom language teaching materials (2003, pp. 387-388).

The next category deals with the teaching of culture. It has been agreed that any ELT material should be sensitive about the cultural plurality that characterizes the world we live in today. Seelye (1993), for example, has spoken of seven goals every cultural instruction should attain, proposing that these goals should lead learners to the ultimate goal of cultural literacy. However, because the book under scrutiny is not a book specifically on the teaching of culture, the authors of this paper have centered their analysis on some elements that, according to Tomlinson (2003), should be included in every language coursebook that claims to be culturally sensitive. Such elements might include determining the cultural focus of the book, appropriacy and relevance of materials to the learner's cultural reality, the effect of materials on the learner's cultural sensitivity, the avoidance of "stereotyped, inaccurate [...] or offensive images of gender, race, social class or nationality", and many others (2003, p. 52). Additionally, a culturally sensitive book should help create the conditions to make cultural instruction transcend the boundaries of the mainstream cultures that most frequently are found in traditional textbooks (e.g., the cultures of the USA, Canada, and England), as well as to engage learners in making critical connections between the cultural elements portrayed in the book and those of their surrounding environments.

Besides conforming to principles of cultural plurality, understanding and competence, a language coursebook must point at developing critical thinking skills that are beyond the mere act of transmitting an intelligible and grammatically accurate message. Critical thinking skills comprise, therefore, the next category of our framework. According to Tomlinson, these skills must be tackled in ELT materials by offering learners the opportunity to: make decisions about learning, be independent language users, discover "their learning styles and preferences, study habits and learning strategies", think "about their learning process", assess their language learning strategies, and, among many others, engage in processes of "self-monitoring and feedback" (2003, p. 48). While we are aware that critical thinking skills are difficult to assess at first glance, our analysis is committed to identifying those methodological elements that foster the development-at least subtly—of such crucial skills.

Winding up the framework for ELT materials development and evaluation is the category of assessment considerations and supplementary materials. Authors such as 
Coombe, Folse, and Hubley (2007) and McGrath (2002) have addressed the value of assessment resources in the context of language teaching. McGrath, more specifically, has claimed that effective ELT materials must come with "additional components" such as teacher's books, tests, and cassettes, and that they need to ensure all of these materials are "suitable for self-study" (2002, p. 33). In the article entitled Selection of Materials, Rubdy (2003) reaffirms Coombe, Folse, and Hubley, and McGrath's claims that effective coursebooks need to provide additional materials such as online resources, tapescripts, answer keys, vocabulary lists, a teacher's book, online resources, self-assessment checklists, and a great many other resources that, together with the principles discussed herein, can help us better teach the language competencies that today's society requires.

While the principles hitherto reviewed provide a reasonably solid idea of the essentials behind ELT materials design and evaluation, there are limits to how far they can be taken. Firstly, we need to bear in mind that most of these insights have been drawn from research conducted in contexts out of the Costa Rican educational landscape. Therefore, it would be hasty to confer them a normative nature, especially because, as it is widely known, materials design, evaluation, and selection depends on the local dynamics where teaching is to unfold. As researchers, we acknowledge the limitations this framework may present when used in the context of Costa Rican education. We also acknowledge that other authors have proposed other frameworks, but we believe that the one devised herein will set the underpinnings of a principled and up-to-date analysis of not only the book under scrutiny, but of many other ELT materials.

\subsection{The English Teaching Major Curriculum}

The discussion that follows has been based on the content of the ETM's curriculum where the study was conducted and is intended to synthesize the theoretical guideposts the ETM is based upon.

\subsubsection{Antecedents}

The English Teaching Major at the Bachelor's level where this study has taken place started in 1992. The major was authorized through the act number UD-R-5400-92 with the code number 600116. 


\subsubsection{Objectives}

The major in question has four central objectives. The first one is that graduates from the program be able to deal with the different aspects of the secondary-school English programs. The second one is that graduates develop knowledge regarding the structure, pronunciation, vocabulary and other linguistic and sociolinguistic skills of the English language. The third objective seeks that graduates critically and scientifically evaluate English and American literary works both in their structure and correlations as well as in their extra literary situation. The last objective is that graduates develop oral skills that allow them to express and communicate adequately in English so as to be able to perform jobs other than teaching-related.

\subsubsection{Aims}

The main purpose of the Bachelor's in the English Teaching Major is to contribute to the improvement of the teaching and academic qualifications of secondary school level English teachers. The courses in the program seek the development of integral teaching skills that will result in more effective teaching practices. To this end, academic courses have been included in the study program, which are under the responsibility of the English Section, and others that are part of the Department of Education since those have a pedagogical-curricular orientation.

\subsubsection{Curricular Axes}

Four major curricular axes comprise the pedagogical architecture of this major. The first axis is the humanities one, which includes all the general education courses such as philosophy, history, literature, research methodologies, arts, seminars of Costa Rican reality, and so on. The second axis is the specific or specialty one, in which all the English language courses that are aimed at improving the students' linguistic competences of the target language are included. Such courses include, for instance, oral and written communication courses, phonetics, phonology, and phonetics and phonology laboratory courses. The third axis is the pedagogical one, where all courses in the field of education are grouped. Courses in this axis deal with general pedagogy, psycho-pedagogy, educational research, curricular development, and so on. The last axis is the literature one, where courses on American, British, and comparative literature are included. 


\subsubsection{Methodological Orientation}

The major affords an eclectic teaching methodology where elements drawn from the humanistic philosophy and the constructivist pedagogy are combined. For the purpose of courses related to the specific or specialty axis, the proposed approaches are the communicative and the content-based approaches, with the support of constructivism as a learning theory that frames classroom practices informed also by emerging literature in the field of second and foreign language teaching. All in all, the teaching-learning processes in the major are guided through constructivist and communicative methodologies where the teacher is a guide and facilitator in the educational process while the students are the constructors of their own learning.

\subsubsection{Exit Profile}

In terms of knowledge, the graduate of the program is expected to possess basic skills regarding research and to carry out research in the field of foreign language learning and teaching. They are academically prepared to perform their teaching job at the secondary school levels and are expected to deal with the unexpected in a professional and efficient manner. They are also expected to know the pedagogical and methodological strategies for the teaching of English, as well as to have competent English oral and writing skills.

Likewise, graduates of the program are expected to critically value literary work written in English and to possess the academic knowledge to pursue graduate studies, do educational research, and continuously update and upgrade their professional knowledge. At the cultural level, they are expected to value local culture and to teach it to their students. They are expected to be equipped with knowledge on computers and computer applications so as to use them in their teaching practice. Additionally, they are estimated to efficiently participate in the curricular and cross-curricular activities at the institution where they work. Lastly, the graduate of this major is expected to encourage civic and democratic values as well as respect for the institutions of the Republic amongst their fellow teachers, parents and the community.

Besides the expected exit profile, there are a series of skills, attitudes and values that the graduate should possess. In terms of skills, they should be capable of seeking and maintaining a physical and affective environment that is learning-oriented, being organized and leading groups of students, being capable of synthesizing, being good readers and speakers, being capable of keeping balance between theoretical and practical knowledge, 
showing capacity to deal with teenagers and adults, showing capability for team work and conflict management, showing self-learning capabilities, and possessing research capabilities.

Regarding values and attitudes, graduates of the program will participate in the rearing of the national educational process, be self-secure, get involved with the building of their students' personalities, encourage civic and ethic-professional values, have good interpersonal relations, seek personal growth, keep objective and critical when expressing opinions or making decisions, be creative, be prepared to look for and choose linguistic and pedagogical information, be prepared to easily insert themselves in the dynamics of the social world, and be capable of achieving inter-disciplinarily knowledge to change the dynamics of the sciences and society at large.

All in all, one could say that the ETM's curriculum of the university where this study has taken place affords a philosophy of teaching and learning that is responsive to and consistent with the economic, social and cultural reality that surrounds the educational system of Costa Rica.

With this in mind, the section that follows discusses major studies, findings, and conclusions drawn in the field of ELT materials development and evaluation in order to identify advancements in the area, as well as to pinpoint theoretical gaps that are yet to be included in the research agenda of Applied Linguistics.

\subsection{Recent Studies in the field of ELT Materials Development and Evaluation}

The rapid advancements in materials development for language teaching have brought about a number of publications addressing different issues within this area of applied linguistics. Some recent publications in the field include-but are not restricted to- those by Gray (2000), Sahragard, Rahimi, and Zaremoayeddy (2008), Johnson et al. (2008), Tuan (2012), Gómez (2012), and many others, and they all have taken the challenge to illuminate the field of ELT materials development for classroom use. In his article, "The ELT Coursebook as Cultural Artefact: How Teachers Censor and Adapt", Gray (2000) takes a stand in examining what teachers think about the cultural content in ELT coursebooks in Spain, as well as what they should do with the content they do not feel comfortable with. Using qualitative and quantitative research methods, the author inquired on whether learners accept, interpret, and reject content openly or in an unspoken way; he also inquired on what motivates when they set about changing a coursebook or part of it. The findings of the 
research revealed that out of the 20 teachers who participated in the study, the majority reported to feel uncomfortable with using the cultural content of the book, especially the areas pertaining to stereotypical representations and irrelevant or sexist content. The author explains that this censorship may have occurred because all of the teachers worked in the private sector, where teachers are trained to develop linguistic, not cultural content. The author concludes that more critical engagement is needed in ELT coursebooks so that students engage in challenging the cultural information offered in them. Tuan (2012) has conducted a similar study at Hung Vuong University, Vietnam. Using teachers and students as participants for the study, the author administered questionnaires that appraised teacher and students' attitudes towards the book High Season. Upon evaluating attitudes towards categories such as the layout, the content of the book, preferred themes, authenticity of language used in the book, level of relevance of language, and so on, the author concluded that while both teachers and students reported to have positive attitudes towards most of the categories inquired, they sense weaknesses in the themes presented in the books, mainly because there are "unmatched preferences between teachers and students" (p. 203). The author advices that teachers not impose their views on the themes covered in class and that they continue to do research on student and teacher preferences towards classroom materials so that these discrepancies can be solved. Lastly, Tuan highlights the importance of background knowledge activities in the comprehension and processing of the material and encourages teachers to use pre-task activities that cater to this need. In a similar publication, Sahragard, Rahimi, and Zaremoayeddy (2008) set out to evaluate the Interchange Series $\left(3^{\text {rd }}\right.$ Edition), "written by Richards, Hull and Proctor in 2006" (p. 38) by using Littlejohn's (1998) framework for materials evaluation. The authors found out that while the textbook claims and manages to: Be communicative and task-based, include "high-interest topics, focus both on fluency and accuracy [...]" (p. 38); they identified weaknesses in interaction skills, lack of linguistic sequence from unit to unit, lack of opportunities for learners and teachers to choose the tasks, and limited expected output on the part of the students (pp. 50-51). This study suggests that, as it is frequently acknowledged by experts in the field, there is no such thing as the perfect book, and that, although a book may offer some degree of compliance with materials development principles, areas of improvement will always be identifiable if in-depth evaluation is conducted.

In another study, Johnson et al. (2008) assessed textbook evaluation techniques used by expert and novice teachers at "Lancaster University's Department of Linguistic and English 
Language" (p. 157). By videotaping and transcribing think-aloud protocols where the participants verbalized their experiences as textbook evaluators, the authors were able to identify five salient categories in the data regarding textbook evaluation: "sequence of evaluation, teacher preferences, use of terminology, methodological concerns, and flexibility in usage" (p. 159). The authors conducted in-depth analysis of these categories and were later able to suggest that expertise studies like the one they conducted provide insights regarding potential teacher training programs for the participants. They also suggest that if teachers are to be trained in textbook evaluation, the use of verbalization can help determine "how experienced evaluators operate [...], what procedures they use and what issues they focus attention to" (p. 162). In this manner, the authors claim, the evaluators can take an indepth approach to evaluation where they are able to go beyond the claims made by the author and the publishing house and to be able to assess whether the book actually lives up "to the claims that are being made for them" (McGrath, 2002, p. 27-8, in Johnson et al., 2008, p. 162). Gómez (2012), in a study that reported the results of an action research carried out in an advanced EFL classroom in Bogotá, Colombia, has proposed the inclusion of more authentic literary texts in the EFL classroom through the use of constructivist approaches to language teaching. He has also highlighted that way too many textbooks have centered in developing the linguistic competencies of learners but have overlooked the cultural dimension that is inherent in every language learning experience. He concludes that combining the use of authentic literary texts (being authenticity an aspect of ELT materials long discussed in the literature of materials development and evaluation) with appropriate teaching methodologies allows for the achievement of not only linguistic but also cultural and social goals of language instruction. The empirical research on ELT materials development and evaluation to date has tended to focus on few-and for the most part isolated- elements of language instruction, with a strong inclination for materials adaptation, perceptions about these materials, and approaches to materials evaluation. The studies herein discussed are all a fair attempt to illuminate the many issues that revolve around the field of ELT materials evaluation and development. Nonetheless, only one of them (Sahragard, Rahimi, and Zaremoayeddy's) has focused on evaluating the compliance of a coursebook with principles of materials development and evaluation, which can be equated with the status quo of language coursebook evaluation in Costa Rica and, in particular, in the setting where the present investigation has taken place. Thus, the authors of the present paper hope that the framework for the evaluation of the book Interactions 1 serves a departing point to both 
supplement the available frameworks for materials evaluation already proposed by experts in the field (e.g., Tomlinson (2003), Rubdy (2003), McDonough and Shaw (2003), and many others) and enlarge the amount of empirical evidence on ELT materials development and evaluation. Upon having discussed the framework for the evaluation of the book of this investigation, provided an overview of the ETM's language curriculum, and given an account of recent empirical studies in the arena of ELT materials development and evaluation, the next section will provide an account of the methodological framework used for the completion of this research.

\section{Methodology}

\subsection{The Research Methodology}

This paper set off to analyze the consistency of the textbook Interactions 1 with both current language materials evaluation and development theory as articulated in a fifteencriteria framework and the proposed English Teaching curriculum at the West Branch of the University of Costa Rica. In terms of its depth, the study is conceived as descriptive, which, according to Barrantes (2013), seeks to describe phenomena. For the purpose of collection, analysis of data, the study undertook a mixed approach to research because, as agreed by Hernández Sampieri (1991), it favors the triangulation of quantitative and qualitative data in the analysis. More specifically, the study used a QUAN-QUAL model that combined features of both quantitative (QUAN) and qualitative research (QUAL) into two data collection phases as described by Gay, Mills, and Airasian (2009). In the first phase, numerical data were recorded via analyzing the degree of compliance of the book with current ELT materials development and evaluation; in the second one, qualitative annotations were used to further back up and cross check the numerical data recorded in the first phase which, incidentally, allowed for an in-depth interpretation of the congruence-or lack of it- between the English Teaching curriculum and the book under scrutiny. A last step into the process of triangulation consisted of analyzing the results in light of current research, so that points of comparison and mismatches could be identified between the results of the present paper and those of related studies.

\subsection{The Context of the Study}

The study was conducted at a public university in Costa Rica during the first term of 2014, where the book Interactions 1 is used as the core textbook in oral communication 
courses. The Major is based upon the theoretical foundations of four major axes: The Humanities, the English, the Pedagogy, and the Literature axes (Carrera Bachillerato $y$ Licenciatura en la Enseñanza del Inglés, p. 7); each of them offering courses aimed at preparing English teachers that cater to the demands of today's globalized world. Additionally, the Major uses an eclectic teaching methodology, whose foundations come mainly from the humanistic and constructivist approaches (Carrera Bachillerato y Licenciatura en la Enseñanza del Inglés, pp. 7-8).

\subsection{The Data Collection Instrument}

The instrument comprised a total of fifteen categories: The author and the publishing company, the cost of the book, the layout, the setting in which the book is being used, congruence between the book's syllabus and the curriculum objectives, the target audience, methodological considerations about learning and teaching theory, general and specific instructions, the role of grammar, the teaching of culture, critical thinking, assessment considerations, and supplementary materials. Each category included different criteria that sought to assess the degree of compliance of the book with the principles aforementioned (see appendix 1).

Following each of the categories, space for qualitative annotations was provided so that the numerical data could be further described and explained, as can be seen in the procedures section, as well as in appendix 1.

\subsection{Procedures}

For purposes of tabulation and statistic practicality in the first stage of the data analysis, the degree of compliance was ranked as: Yes (= 2 points), No (= 0 points), and Partly (1 point). This allowed giving a raw score from 1 to 100 to each of the categories inquired which made it easy to conduct further discussion of the results. As for the second stage, a section for comments and recommendations was included at the end of every category so as to back up the numerical data with qualitative information that would allow a more balanced analysis of the overall degree of compliance of the book with the theoretical principles discussed in the review of the literature. 


\subsection{Validation of Instrument and Methodology}

Four procedures were used to account for instrument and methodological validity. Firstly, the methodology was validated by checking full parallelism between research question, research objectives, and its appropriateness with the research design selected. Secondly, criteria to evaluate the textbook were drawn from the review of the literature on materials development and evaluation. Such criteria were articulated as a fifteen-category framework. Thirdly, the instrument was pilot tested by analyzing a textbook called NORTHSTAR 4: Reading and Writing, in order to identify areas of improvement of it and to satisfy inter-rater reliability. Lastly, the instrument was assessed for content validity by using an adaptation of an evaluation checklist proposed by Gay, Mills, and Airasian (2009, p. 535) (see appendix 2).

\subsection{Data Analysis Techniques}

The data analysis that follows uses descriptive statistics to present and discuss the results. It also makes use of numerical data accompanied by verbal descriptions and tables to display the data, which resulted from the statistical and descriptive information recorded through the assessment instrument described above in this section.

\section{$4 \quad$ Analysis of the Results}

First of all, this section presents an analysis of the level of compliance of the book Interactions 1 with 15 categories identified as essential for a course textbook; namely, the author and publishing company, the cost, the layout, the setting, the syllabus and the objectives, the target audience, methodological considerations, general and specific instructions, the role of grammar, the teaching of culture, critical thinking, assessment considerations, and supplemental materials. Second, an analysis of the extent to which the ETM's curriculum components match the Interactions 1 book used as the core textbook in the major where the study was run is also presented in this section.

For the purpose of clarity, the researchers have resolved to group data into three categories operationalized as follows: The highest third, which depicts criteria ranking between 66.7 and $100 \%$ degree of compliance with the desired principles for materials development and evaluation, includes an analysis of the author and the publishing company, the syllabus and the objectives, general and specific instructions, and the role of grammar; the middle third, which describes criteria ranking between 33.4 and $66.6 \%$; , includes an 
analysis of the layout, the setting, the target audience, methodological considerations, the teaching of culture, and critical thinking; and the lowest third, which displays criteria ranking between 0 and $33.3 \%$ percent, provides an analysis of the cost, assessment considerations, and supplementary materials.

\subsection{Interactions 1 and Principles of ELT Materials Development and Evaluation}

\subsubsection{Analysis of the Highest Third}

\subsubsection{The Author and Publishing Company}

The level of compliance regarding the author and publishing company was found to be $85 \%$. The book features not just a single author but a group of them which translates in a large combined bulk of experience. Besides, the publishing company is well known and reputable. A down fall is that shipping of the book in large quantities is not too efficient which often makes having the book available at the beginning of the term difficult. In general, regarding the author and publishing company criterion the book was found to highly comply with the criteria described by Tomlinson (2003) in the literature.

\subsubsection{The Syllabus and Book Objectives}

The book's level of compliance with these criteria showed to be $75 \%$. While this seems a high number, it was clear that there is no direct correspondence between syllabus and perceived book objectives. In addition, though some of the contents in the book match the contents in the syllabus, many contents in the book are left out of the syllabus. This all means that in terms of the syllabus and the course objectives the book somewhat contradicts Tomlinson's (2003) recommendations.

\subsubsection{General and Specific Instructions}

Adding up to $71,4 \%$ degree of compliance, numerical data in this section depict a more promising scenario in terms of appropriateness between the book and the course in which it is being used. Must-improve areas have to do with format, specifically with bulleting of specific instructions so that they become more clear and self-standing.

\subsubsection{The Role of Grammar}

The degree of compliance for this criterion was $75 \%$. Though the numbers are high, a few downfalls were identified regarding this criterion: The students in the groups the book is 
used in exhibit heterogeneous proficiency levels and although some contextualization is present, many of the activities are rather artificial and not real-life-like, a result that does not seem to correspond with Ellis' (2010) recommendations for the role of grammar in a true communicative and meaningful learning scenario.

\subsubsection{The Teaching of Listening}

The extent to which the book complies with this category was identified to be $90 \%$. It was noticed that most listening tasks in the book are academic and that, very few, if any, are real-life oriented. Such finding deviates from what Vandergrift (in McDonough and Shaw, 2003) conceives as effective teaching of listening because the book leaves important competencies unattended, namely those which are not academic in nature. That said, graph 1 below details the quantitative data analyzed for the highest third.

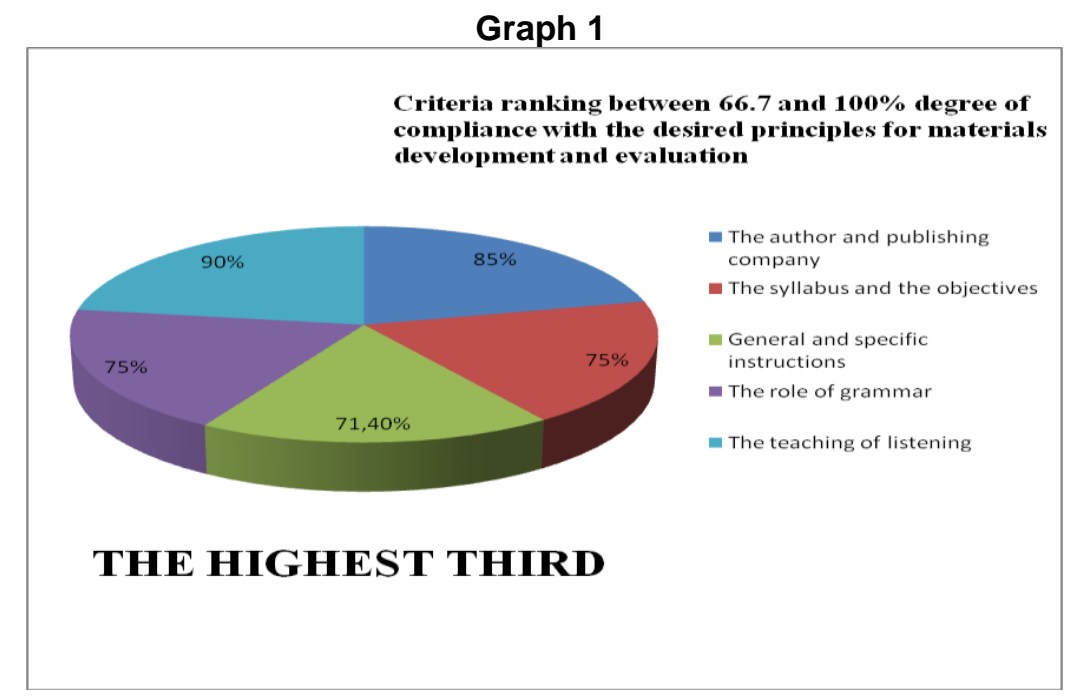

Source: Researchers' own design

\subsubsection{Analysis of the Middle Third}

\subsubsection{The Layout}

While the book conforms partly with principles pertaining to layout and its correspondence with the context and needs of the students, areas such as the color, durability, font size and color, and attractiveness for the population in which it is being used need to be improved. The book only complies in 50\% with materials evaluation principles discussed by McGrath (2002, p. 29). 


\subsubsection{The Setting}

A $66.66 \%$ degree of compliance was observed for the criterion of setting. Arguably, the level of compliance for this criterion was not higher because the textbook has been created for an international audience, mostly for use in the ESL classroom. Also, the cultural content of the book does not fully address Costa Rican students nor does the book fully match the curriculum of the course it is being used in. Therefore, a discrepancy was observed between this book and Tomlinson's (2003) recommendations for the considerations regarding the setting.

\subsubsection{The Target Audience}

For the target audience, the degree of compliance identified was $62.5 \%$. Possibly this is so because students come with different proficiency levels to the class the book is used in and therefore the book matches some of the students' levels but not all of them. Moreover, the book is a bit outdated and the contents are not always motivating to the students. Also, the textbook is not an EFL text. Conclusively, regarding the target audience the book highly fails to observe McDonough and Shaw (2003) and McGrath's (2002) recommendations for a course textbook. See table 6 below.

\subsubsection{Methodological Considerations}

\subsection{Language Learning Theory}

The total degree of compliance for language learning theory was found to be $50 \%$. The book complies with most of the assessment criteria in a partial manner. Must-improve areas have to do with the need for deep processing intake, often associated with the affective engagement of the learner (Tomlinson 19); also, areas to improve include the book's potential to trigger connections with both background knowledge and the usefulness of the subject matter in the students' future lives. Finally, the book fails to address the students in a personal manner so that personalization of knowledge can take place, which is also related to the need to appeal to students' "emotions, attitudes, opinions and ideas", as suggested by Berman (1999, p.2, cited in Tomlinson, 2003, p. 20).

\subsection{Language Teaching Theory}

Numerically speaking, the data analyzed in this category shows a $42,8 \%$ degree of compliance of the book in terms of language learning theory said to be effective for ELT. 
Contrastingly, the qualitative analysis depicts that while the book embraces some of the traits of the CLT approaches, many of the tasks and exercises fail to offer true communicative opportunities where the students can see and process language meaningfully. Also, a weakness of the book in terms of the teaching theory is that it tends to focus more on form than in meaning, and it does not offer true contextualized grammar exercises as proposed by Ellis (2010). The other criteria that have been ranked "partly" have shown to conform to the assessment criteria in a partial way, but they still fail to account for a full compliance with the desired criteria discussed by theory on methodological considerations.

\subsubsection{The teaching of Speaking}

The degree of compliance for this category was found to be $60 \%$. Because the book is outdated, it fails to fully attend to current student's needs and wants. Also, since the book is aimed at an international audience, it does not directly address local students' needs. Likewise, the speaking tasks are somewhat scripted and not so authentic in nature, a finding that digresses from what Dat (2003) considers effective speaking tasks should possess as stated in his five-dimension framework for ELT materials.

\subsubsection{The Teaching of Culture}

The percentage for the total degree of compliance of this category depicts a relatively positive outcome $(62,5 \%)$ in terms of the tackling of culture in this book. In item 2 , the degree of compliance has been ranked partly because while the book does promote tolerance and open-mindedness, it fails to account for the goals of cultural instruction discussed and proposed by Seelye (1993). Likewise, with regard to items 4 and 5, the degree of compliance has been ranked as partly because the tasks enable learners to reflect upon their cultural realities and practices only to some degree, often overlooking the goal of cultural literacy that ELT coursebooks are expected to pursuit. As for items 7 and 8, the degree of compliance is only partial because the learners are confronted only with a surface understanding of cultures and cultural realities, and the connection between what the students learn from the book in class and the usefulness of it outside the classroom needs improvement as well. Taken together, the qualitative and quantitative analysis of this category suggests that the teaching of culture is addressed only at a partial level in this book. 


\subsubsection{Critical Thinking}

Numerical data in this section reveal that the degree of compliance of the book with the desired criteria for critical thinking adds up to 66, 6\%; a relatively positive outcome considering that critical thinking is a complex process that requires more than exposure to higher order tasks. As for the qualitative component analyzed in the section, annotations reveal that in the items ranked as "partly" in this section $(1,2,5$, and 6$)$ the book complies with the desired criteria to some extent, but there are areas that must be improved. For instance, criteria reviewed in Sevilla and Méndez (2013), such as the making of critical connections between the subject matter and the students' social and national realities, guidance on how to articulate critical arguments in the classroom, as well as how to state logical arguments in the writing tasks are all areas that still need to be fine-tuned for a more thorough accomplishment of critical thinking. Graph 2 below details the quantitative data analyzed for the middle third.

\section{Graph 2}

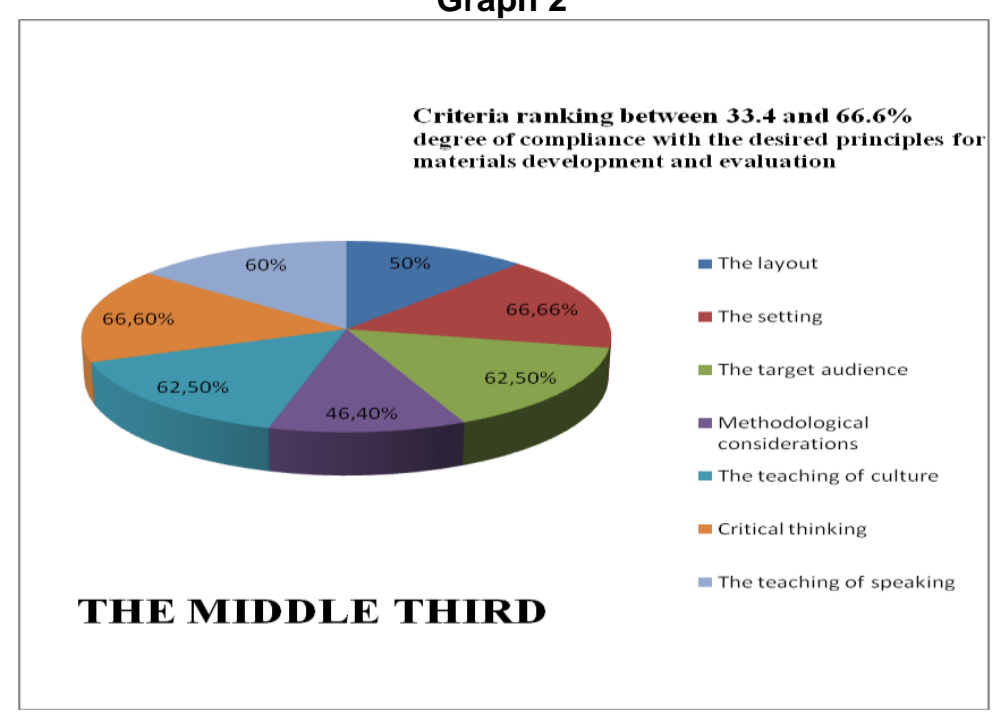

Source: Researchers' own design

\subsubsection{Analysis of the Lowest Third}

\subsubsection{The Cost}

In terms of the cost, the degree of compliance was found to be $25 \%$. This low level of compliance is due in part to the fact that the book's edition in current use at the West Branch does not offer online resources, but mostly to the fact that the price of the book in the market is very high for the student population. Thus, in terms of cost the book proved not to fulfill McGrath's (2002) recommendations for a course textbook. 


\subsubsection{Assessment Considerations}

The extent to which the book was observed to comply with this criterion was $0 \%$. Failure to comply with this criterion is due to the fact that the book is not accompanied by any of these resources: self-assessment instruments like scales, performance checklists, and reflection forms; a progress tests bank, an achievement test bank, a review test bank; nor an answer key to the progress, achievement, and review tests. Shortly, it was not possible to observe any of Coombe, Folse, and Hubley's (2007) recommendations regarding assessment considerations in this book.

\subsubsection{Supplementary Materials}

The numerical data for this section depicts that the book complies with $31,8 \%$ of the desired criteria in terms of supplementary materials, a low ranking considering the central role that supplementary materials have been recently ascribed in the world of ELT. Collaterally, the qualitative annotations reveal that elements such online components, extra vocabulary, composition and reading materials, test generators, CDs with extra tasks, a critical skills section, and a further research section are not included at all in this coursebook package; and that because the series does not include a workbook, an answer key for it has therefore not been supplied. Taken together, the results from this section suggest low attainment of the materials evaluation principles discussed in recent theory of ELT materials (e.g., McGrath, 2002). Graph 3 below details the quantitative data analyzed for the lowest third.

\section{Graph 3}

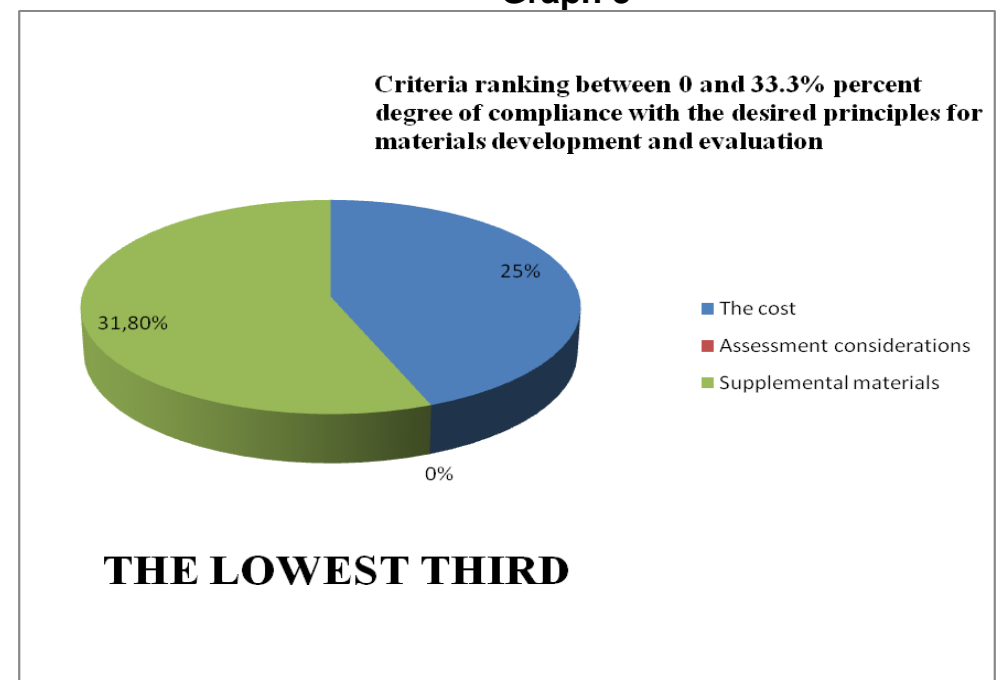

Source: Researcher's own design 
In the preceding pages, the results of the analysis of compliance levels between the book in question and principles of ELT materials development and evaluation have been presented for each set of criteria operationalized as: The highest third, the middle third, and the lowest third. Henceforth, as a summary, graph 4 below depicts the degree of compliance of Interactions 1 with all of the components devised in our framework for ELT materials development and evaluation.

Graph 4

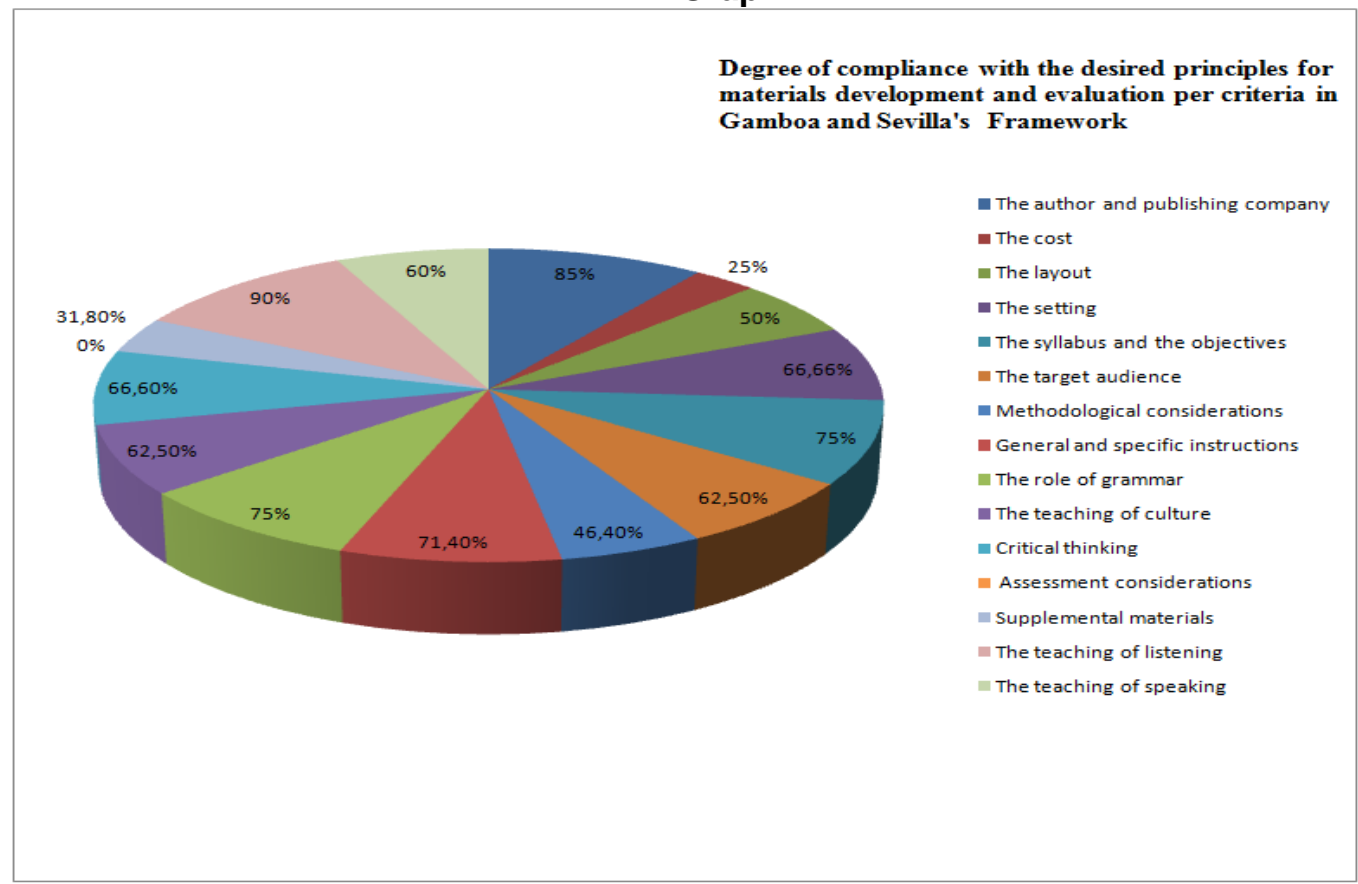

Source: Researchers' own design

\subsection{The English Teaching Major Curriculum vs Interactions 1}

Another component that was analyzed in the present study was the extent to which the ETM's curriculum components match the Interactions 1 book used as the core textbook in the oral Communication courses in question. Thus, four categories were identified as points of convergence between the book and the ETM's curriculum: The objectives, the curricular axes, the exit profile, and the methodological orientation of the major.

Firstly, in terms of linguistic development, the elements in the ETM's curriculum that are dealt with in Interactions 1 include: Two of the objectives, the second curricular axis, and one of the components in the exit profile. The book appropriately tackles these three categories since it exhibits a series of features that assist the learners in their development of English language skills. As evidence to this finding, the publishers of the book (i.e., McGraw Hill Inc.) state that: 
each chapter begins with a Getting Started section that introduces the chapter theme and provides an opportunity to work with all four language skills. Getting Started sections feature two video clips that immediately capture students' interest. As students continue working through the chapter, the plot line of the video is expanded upon in grammar, reading, and listening/speaking activities. Grammar points are presented in clear, easy to read charts, and are followed by a variety of activities, many designed for pair or group practice. Reading sections encourage the use of reading strategies and include pre- and post-reading exercises. Listening sections contain a variety of audio formats including dialogues, interviews, announcements, and lectures. Communicative speaking activities include role-plays, interviews, discussions, and more. Writing sections take a step-by-step approach in which students are guided through the different stages of writing and rewriting, and through a variety of different writing genres. Journal writing topics in each chapter encourage students to write freely on a given subject related to the chapter theme, and provide an opportunity to practice new and acquired skills and structures. All journal assignments call for student-centered responses [...]. (Interactions One, n.d., parr. 7)

Along the same lines, the other point at which Interactions 1 and the major's curriculum intersect is the category of methodological orientation. Here, a high degree of correspondence was identified between the methodology proposed in the ETM's curriculum and the one Interactions 1 claims to be informed by. The ETM's methodology is eclectic in principle where elements drawn from the humanistic philosophy and the constructivist pedagogy are combined. Regarding the methodological approaches, the one used in the major is the communicative and the content-based approaches. Conversely, the methodology in Interactions 1 is theme-based. The book incorporates communicative activities and skillbuilding exercises to boost academic success. Because the activities and methodologies in the book are components of both the communicative approach and an eclectic methodology, a clear correspondence can be established between the methodology in the book and that of the ETM.

Upon having scrutinized the two dimensions this research inquiry is based upon, the forthcoming section presents the conclusions, discussion and implications of the study. 


\section{Conclusions, discussion, and Implications}

This study set out to examine how suitable the book Interactions 1: Integrated Skills as the core textbook in an oral communication class in the English Teaching Major at a public university in Costa Rica is. Briefly, the researchers have scrutinized the methodological makeup of the aforementioned book for congruence with theory on materials development and evaluation and its consistency with the ETM's curriculum. Thus, this section features the most relevant conclusions and implications of the study. Such conclusions and implications have been organized according to the way the analysis of the results was presented above in this paper. One of the most important conclusions is that criteria contained in the highest third exhibits high, though not full, degrees of compliance with current principles on materials development and evaluation. For example, the authors were found to have a lot of experience and the publishing company proved reputable and well-known. The general and specific instructions, likewise, highly comply with such theoretical principles. Nonetheless, some limitations were also identified. For instance, the book objectives and those of the syllabus do not directly correspond with one another while the role of grammar exhibits contradictions with theoretical principles because some of the activities in the book are rather artificial. All of this means that because of the high degree of compliance of the criteria in the highest third with theoretical principles of materials development and evaluation, the book proved to be an acceptable, but naturally not a perfect, choice to be used as the core textbook in the oral communication course. Another major conclusion is that, in terms of the middle third, the degree of compliance of the criteria contained in this set with theory on materials development and evaluation is only partial. The layout of the book, for instance, is only partly appropriate and appealing for the population it is being used with. Also, in terms of the setting it was found that the book addresses and international audience - not a local Costa Rican one - and, thus, some of their needs are neglected or left aside. Besides, some of the contents in the book were found to be outdated and therefore unappealing or irrelevant to the students. The fact that the book is meant for a homogeneous audience in terms of proficiency level is another issue here since the students in the group have dissimilar proficiency levels. In addition, because many activities in the book do not provide for true communication opportunities and since difficulty to personalize knowledge was identified, theoretical principles regarding methodological considerations were not fully met. Thus, it is pertinent to assert that the analysis of the criteria contained in the middle third proved that the book Interactions 1 is not very appropriate to be used as the core textbook of the course. 
Regarding the level of compliance of the coursebook with principles on materials development and evaluation, a last conclusion is that the criteria within the lowest third comply very little with such principles. For instance, the amount of supplementary materials that accompany the book is very limited. Neither on-line nor assessment resources were available; and the book was found to be expensive considering the limited amount of supplementary resources it offers. It falls on teachers and stakeholders to make the necessary adaptations and to supply for the scarcity of supplementary materials. Otherwise, the book would not serve the purpose it purports to serve.

Regarding the extent to which the ETM's curriculum components match the Interactions 1 book used as the core textbook in the Oral Communication I course two conclusions were made. First, Interactions 1 appropriately deals with the language components contained in the ETM's curriculum since it parallels with two of its objectives, the second axis, and one of the components in the exit profile of the program. Second, a clear correspondence was established between the methodology in the book and that of the ETM. On the whole, Interactions 1 reasonably complies with the language components requirements in the ETM's curriculum. Taken together, findings imply that, because the limitations identified affect very sensitive areas of language learning, the use of the book Interactions 1 in the context where it is being implemented needs to be reconsidered. The authors of this research suggest that prospective coursebook and ELT materials adoption in this university be made on the basis of research informed decisions.

\section{Limitations and Future Research}

While this study has managed to examine the object it purported to, there are limitations at two levels that must be kept in mind. The first one is in terms of how much the study was able to explore. It was not possible to examine the institutions authorities' backgrounds in terms of their training and expertise in materials assessment and selection. Future research should therefore address this gap by conducting in-depth interviews so that a clearer understanding of the relationship between materials selectors' training on ELT materials assessment and the suitability of the books they select can be determined. Likewise, students' perceptions regarding the suitability of the textbook were not studied. Further investigations should undertake an exploration of this by conducting semi-structured interviews and other qualitative methods that allow for a more naturalistic understanding of the issue. The second level has to do with the applicability of the framework used for the 
analysis of the textbook. As discussed in 2.1 in this paper, caution is advised as the framework was based on principles conceived outside the Costa Rican context. It would be pretentious, for instance, to think of this as a universalizing gauge. This makes particular sense if we keep in mind that in language education theoretical principles need to be adapted to match the specific needs and dynamics where teaching and learning occurs, just like in social sciences in general. All things considered, further studies and similar frameworks may help both to make more research-informed decisions regarding the selection, implementation and evaluation of ELT materials, and also strengthen the emerging body of literature on materials development and evaluation; a subject area that, to date, has remained somewhat unexplored.

\section{References}

Baker, Linda, Hartman, Pamela, Jack, Darcy, Kirn, Elaine, Most, Paul, O'Sullivan, Jill, Pavlik, Cheryl, Segal, Margaret, and Tanka, Judith. (2003). Interactions 1: Integrated skills edition. New York: McGraw-Hill.

Barrantes, Rodrigo. (2013). Métodos de estudio a distancia e investigación: A la búsqueda del conocimiento científico. San José: Editorial Universidad Estatal a Distancia.

Coombe, Christine A., Folse, Keith S., and Hubley, Nancy J. (2007). A Practical Guide to Assessing English Language Learners. Ann Arbor, Mich: University of Michigan.

Dat, Bao. (2003). Materials for Developing Speaking Skills. In Tomlinson, Brian, Developing Materials for Language Teaching (pp. 375-393). London: Continuum International Publishing Group.

Ellis, Rod. (2010). Second language acquisition research and language-teaching materials. In Nigel Harwood, English Language Teaching Materials (pp. 33-57). New York: Cambridge University Press.

Gay, Lorraine R., Mills, Geoffrey E., and Airasian, Peter W. (2009). Educational Research: Competencies for Analysis and Applications. Upper Saddle River, N.J: Merrill/Pearson.

Gómez R., Luis Fernando. (2012). Fostering Intercultural Communicative Competence Through Reading Authentic Literary Texts in an Advanced Colombian EFL Classroom: A Constructivist Perspective. PROFILE Issues in Teachers' Professional Development, 14(1), 49-66. Retrieved from http://www.revistas.unal.edu.co/index.php/profile/article/view/29055

Gray, John. (2000). The ELT Coursebook as Cultural Artefact: How Teachers Censor and Adapt. ELT Journal 54(3), 274-283.

Harwood, Nigel. (2010). English Language Teaching Materials. New York: Cambridge University Press. 
Hernández Sampieri, Roberto, Fernández Collado, Carlos, and Baptista Lucio, Pilar. (1991). Metodología de la investigación. México: McGraw-Hill.

Interactions Integrated Skills: Key features. (2014). Retrieved from http://www.betterbookprices.com/shop detail.php?CSID=AQOSMQTKB2ASJAKTAQK $\underline{\text { OODCCB\&FVCUSNO }=37059 \& b k n=470807}$

Johnson, Keith, Kim, Mija, Ya-Fang, Liu, Nava, Andrea, Perkins, Dawn, Anne, Margaret, Soler-Canela, Oscar, and Lu, Wang. (2008). A Step Forward: Investigating Expertise in Materials Evaluation. Elt Journal, 62(2), 157-163.

McDonough, Jo, and Shaw, Christopher. (2003). Materials and Methods in ELT. Oxford: Blackwell Publishing.

McGrath, Ian. (2002) Materials Evaluation and Design for language Teaching. Edinburgh: Edinburgh University Press.

Rubdy, Rani. (2003). Selection of Materials. In Brian Tomlinson, Developing Materials for Language Teaching (pp. 37-57). London: Continuum International Publishing Group.

Tomlinson, Brian. (2003). Developing Materials for Language Teaching. London: Continuum International Publishing Group.

Sahragard, Rahman, Rahimi, Ali, and Zaremoayeddi, Iman. (2009). An In-depth Evaluation of Interchange Series ( $3^{\text {rd }}$ Edition). Porta Linguarum, 12, 37-54.

Seelye, H. Ned. (1993). Teaching culture: Strategies for intercultural communication. Lincolnwood, III: National Textbook Co.

Sevilla Morales, Henry, and Méndez Pérez, Geiner. (2013). Proceedings of the 11th Hawaii International Conference on Education: Reading in the EFL Classroom: A Model to Promoting Student centeredness, Self-confidence, and Critical Thinking in Oral Communication Courses. 06-11, Honolulu, Hawaii.

Tuan, Luu Trong. (2012). Coursebook appraisal: Case of Hung Vuong University. Asian Social Science, 8(3), 192-207. Retrieved from http://ccsenet.org/journal/index.php/ass/article/view/15390/10467

Universidad de Costa Rica, Carrera Bachillerato y Licenciatura en la Enseñanza del Inglés. (2013). Antecedentes, Resoluciones, Fundamentos Conceptuales, Objetivos, Fines, Perfiles, Ejes curriculares y Orientación Metodológica. San Ramón, Alajuela: Universidad de Costa Rica. 


\section{Appendices}

\subsection{Appendix 1: Data Collection Assessment Checklist}

Objective: The objective of this instrument is to evaluate the book Interactions I Integrated Skills for its compliance with theoretical principles of materials evaluation and development.

Textbook: Interactions 1 Integrated Skills

Authors: Baker L.R., Hartman P., and others

Publishing house: McGraw-Hill Contemporary

Year/ place of publication: 2003, New York

Edition: Fourth

\section{THE AUTHOR AND PUBLISHING COMPANY}

INSTRUCTIONS: Check the boxes (YES/NO/ PARTLY) according to your appraisal for the textbook's compliance with each aspect inquired. $Y e s=2$ points, $N o=0$ points, and $P$ artly $=1$ point.

\section{CRITERIA ${ }^{3}$}

1) Is the author a well-known and reputable authority in the field of language teaching-learning?

2) Has the author published other coursebooks and ELT materials?

3) Does the author have enough teaching experience?

4) Has the author done considerable research in the field of ELT?

5) Is the author affiliated to a renowned university or institution from the ELT area?

6) Is the publishing house a reputable and well-known one?

7) Does the publishing house have a long publishing record?

8) Does the publishing house have representatives in the country where the textbook is going to be used?

9) Does the publishing house offer fast, affordable shipping of the textbook?

10) Does the publishing house have more than one official distributor in the country where the textbook is going to be used?

Total Points:

\begin{tabular}{|c|c|c|c|}
\hline & YES & NO & PARTLY \\
\hline & & & \\
\hline & & & \\
\hline \multicolumn{4}{|l|}{ area? } \\
\hline & & & \\
\hline & & & \\
\hline & & & \\
\hline & & & \\
\hline ountry & & & \\
\hline & & & \\
\hline
\end{tabular}

General Observations:

\section{THE COST}

INSTRUCTIONS: Check the boxes (YES/NO/ PARTLY) according to your appraisal for the textbook's compliance with each aspect inquired. $Y e s=2$ points, $N o=0$ points, and $P a r t l y=1$ point.

\begin{tabular}{|l|l|l|l|}
\hline \multicolumn{1}{|c|}{ CRITERIA } & YES & NO & PARTLY \\
\hline 1) $\quad$ Can low-income students afford to buy the book? & & & \\
\hline 2) $\quad \begin{array}{l}\text { Are supplementary materials like CDs, workbook, and online resources included } \\
\text { with the purchasing of the book? }\end{array}$ & & \\
\hline Total Points: & Degree of Compliance: \\
\hline
\end{tabular}

\section{General Observations:}

\section{THE LAYOUT}

INSTRUCTIONS: Check the boxes (YES/NO/ PARTLY) according to your appraisal for the textbook's compliance with each aspect inquired. $Y e s=2$ points, No $=0$ points, and Partly $=1$ point.

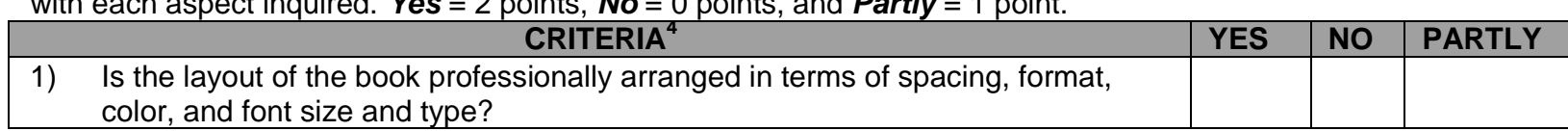

3 Based on Tomlinson's Principles on Materials Evaluation

4 Based on Tomlinson's Principles on Materials Evaluation 


\begin{tabular}{|c|c|c|}
\hline 2) & Is the material of the book hard durable? & \\
\hline 3) & $\begin{array}{l}\text { Are the textbook covers hard and appealing for the type of population that will } \\
\text { be using it? }\end{array}$ & \\
\hline 4) & $\begin{array}{l}\text { Does the book include the following elements? } \\
\text { i. A table of contents } \\
\text { ii. Appealing diagrams, charts, tables, and graphs } \\
\text { iii. Appropriate headings and subheadings both in its presentation and in the } \\
\text { content } \\
\text { iv. A scope and sequence section } \\
\text { v. Other formal elements like acknowledgements, preface, and note to the } \\
\text { teacher }\end{array}$ & \\
\hline \multicolumn{2}{|c|}{ Total Points: } & Degree of Compliance: \\
\hline
\end{tabular}

General Observations:

\section{III.THE SETTING}

INSTRUCTIONS: Check the boxes (YES/NO/ PARTLY) according to your appraisal for the textbook's compliance with each aspect inquired. $Y e s=2$ points, $N o=0$ points, and $P$ artly $=1$ point.

\begin{tabular}{|l|l|l|l|}
\hline \multicolumn{1}{|c|}{ CRITERIA $^{5}$} & YES & NO & PARTLY \\
\hline 1) & Does the textbook match the role of English in the country (i.e.; EFL)? & & \\
\hline 2) & $\begin{array}{l}\text { Does the textbook match the role of English in the school and its position in the } \\
\text { language curriculum? }\end{array}$ & & \\
\hline 3) & Does book match the students' sociocultural environment? & & \\
\hline 4$)$ & $\begin{array}{l}\text { Can the book and its components (e.g., online components) be used with the } \\
\text { teaching resources available in the institution? }\end{array}$ & & \\
\hline 5) $\quad$ Does the book match the course syllabus in terms of its duration? & & \\
\hline 6) $\begin{array}{l}\text { Does the physical environment (e.g., noise, class and room size, heat and cold, } \\
\text { and so on) allow for the appropriate use of the textbook? }\end{array}$ & & \\
\hline Total Points: & Degree of Compliance: \\
\hline
\end{tabular}

\section{General Observations:}

\section{THE SYLLABUS AND THE OBJECTIVES}

INSTRUCTIONS: Check the boxes (YES/NO/ PARTLY) according to your appraisal for the textbook's compliance with each aspect inquired. $Y e s=2$ points, $N o=0$ points, and Partly $=1$ point.

\begin{tabular}{|c|c|c|c|c|}
\hline \multicolumn{2}{|r|}{ CRITERIA 6} & YES & NO & $\begin{array}{l}\text { PARTLY } \\
\end{array}$ \\
\hline 1) & $\begin{array}{l}\text { Is the syllabus oriented towards developing communicative competencies in } \\
\text { learners? }\end{array}$ & & & \\
\hline 2) & $\begin{array}{l}\text { Is there congruence between the syllabus goals and objectives and those } \\
\text { proposed in the textbook? }\end{array}$ & & & \\
\hline 3) & $\begin{array}{l}\text { Are the objectives achievable in the time and context proposed for learning to } \\
\text { take place? }\end{array}$ & & & \\
\hline 4) & $\begin{array}{l}\text { Is the syllabus grounded in learner-centered principles to language acquisition } \\
\text { and learning? }\end{array}$ & & & \\
\hline & I Points: & Deg! & of $\mathrm{Cc}$ & npliance: \\
\hline
\end{tabular}

\section{General Observations:}

5 Based on Tomlinson's Principles on Materials Evaluation

6 Based on Tomlinson's Principles on Materials Evaluation 


\section{THE TARGET AUDIENCE}

INSTRUCTIONS: Check the boxes (YES/NO/ PARTLY) according to your appraisal for the textbook's compliance with each aspect inquired. $Y$ es $=2$ points, $\mathbf{N o}=0$ points, and Partly $=1$ point.

CRITERIA

1) Does the textbook match the intended audience in terms of needs and interests?

2) Has the book been created to teach English as a Foreign Language?

3) Does the textbook match the students' proficiency level?

4) Is the book appropriate for the students' age?

5) Does the book match the students' aptitudes in terms of their main talents and skills?

6) Does the book's content match the learners' reasons for learning?

7) Does the book offer intrinsic and extrinsic motivation that is appropriate for the target population?

8) Is language presented in a way that it allows teachable units and lessons?

9) Do the tasks, activities, and exercises favor different types of learning styles of the pupils?

10) Do the tasks, activities, and exercises appeal to different student personalities?

11) Does the textbook exhibit a congruent relationship between the author's views on language and the methodology proposed, and the way in which the targeted audience learns best?

12) Does the textbook provide supplementary materials that are accessible to the learner such as achievement tests, extra activities, and online resources?

Total Points:

General Observations:

\section{METHODOLOGICAL CONSIDERATIONS}

\section{PART A. LANGUAGE LEARNING THEORY}

INSTRUCTIONS: Check the boxes (YES/NO/ PARTLY) according to your appraisal for the textbook's compliance with each aspect inquired. $Y e s=2$ points, $N o=0$ points, and $P$ artly $=1$ point.

\begin{tabular}{|c|c|c|c|c|}
\hline & CRITERIA $^{8}$ & YES & NO & PARTLY \\
\hline 1) & $\begin{array}{l}\text { Does the book foster deep processing of intake which focuses on its relevance } \\
\text { to the learner's context? }\end{array}$ & & & \\
\hline 2) & $\begin{array}{l}\text { Does the book nurture affective engagement and positive attitudes towards } \\
\text { learning? }\end{array}$ & & & \\
\hline 3) & $\begin{array}{l}\text { Are mental connection between the book's content and the learners' realities } \\
\text { promoted for the learner? }\end{array}$ & & & \\
\hline 4) & Does learning take place in a predominantly experiential manner? & & & \\
\hline 5) & $\begin{array}{l}\text { Are instrumental motivation and integrative motivation present along the } \\
\text { different tasks, activities, and exercises? }\end{array}$ & & & \\
\hline 6) & $\begin{array}{l}\text { Does the book address learners from a friendly, personal voice so as to allow for } \\
\text { better personalization of knowledge? }\end{array}$ & & & \\
\hline 7) & $\begin{array}{l}\text { Does the book promote multidimensional processing of learning (e.g., sensory } \\
\text { imaging, effective association, and use of inner voice)? }\end{array}$ & & & \\
\hline \multicolumn{2}{|r|}{ Total Points: } & \multicolumn{3}{|c|}{ Degree of Compliance: } \\
\hline
\end{tabular}

\section{General Observations:}

7 Based on McGrath's Principles on Materials Evaluation

8 Based on Tomlinson's Principles on Materials Evaluation 


\section{PART B. LANGUAGE TEACHING THEORY}

INSTRUCTIONS: Check the boxes (YES/NO/ PARTLY) according to your appraisal for the textbook's compliance with each aspect inquired. $Y e s=2$ points, $N o=0$ points, and $P$ artly $=1$ point.

\begin{tabular}{|l|l|l|l|}
\hline \multicolumn{1}{|c|}{ CRITERIA $^{9}$} & YES & NO & PARTLY \\
\hline 1) & Is the textbook grounded in CLT approaches? & & \\
\hline 2) & Are exercises in general focused on meaning rather than on form? & & \\
\hline 3) $\begin{array}{l}\text { Does the textbook offer a variety of tasks both focused and unfocused, as well } \\
\text { as contextualized grammar exercises? }\end{array}$ & & & \\
\hline 4) $\begin{array}{l}\text { Do tasks and activities allow for meaningful connections with the students' } \\
\text { personal experiences? }\end{array}$ & & \\
\hline 5) & $\begin{array}{l}\text { Are tasks and activities arranged in a way they foster the integration of different } \\
\text { skills? }\end{array}$ & & \\
\hline 6) & $\begin{array}{l}\text { Does the teaching philosophy along the book allow for both task-based and } \\
\text { task-supported language teaching? }\end{array}$ & & \\
\hline 7) Does the book include both interpretation and conscious-raising tasks? & \multicolumn{2}{|l|}{} \\
\hline Total Points: & Degree of Compliance: \\
\hline
\end{tabular}

\section{General Observations:}

\section{GENERAL AND SPECIFIC INSTRUCTIONS ${ }^{10}$}

INSTRUCTIONS: Check the boxes (YES/NO/ PARTLY) according to your appraisal for the textbook's compliance with each aspect inquired. $Y e s=2$ points, $N o=0$ points, and Partly $=1$ point.

\begin{tabular}{|l|l|l|l|}
\hline \multicolumn{1}{|c|}{ CRITERIA $^{\text {11 }}$} & YES & NO & PARTLY \\
\hline 1) $\quad$ Are the instructions succinct? & & & \\
\hline 2) $\quad \begin{array}{l}\text { Are the instructions sufficient as to guide students into doing exactly what they } \\
\text { are meat to do? }\end{array}$ & & \\
\hline 3) $\quad$ Are instructions self-standing? & & & \\
\hline 4) Are specific instructions separated by using bullets, numbers, or letters? & & & \\
\hline 5) Are instructions ordered sequentially according to what they are expected to do? & & & \\
\hline 6) $\quad \begin{array}{l}\text { Are instructions focused on what the students should do instead of what they } \\
\text { should not do? }\end{array}$ & & \\
\hline 7) Are the instructions written in a clear and grammatically correct way? & & \\
\hline Total Points: & Degree of Compliance: \\
\hline
\end{tabular}

General Observations:

\section{THE ROLE OF GRAMMAR}

INSTRUCTIONS: Check the boxes (YES/NO/ PARTLY) according to your appraisal for the textbook's compliance with each aspect inquired. $Y e s=2$ points, $N o=0$ points, and Partly $=1$ point.

\begin{tabular}{|ll|l|l|}
\hline \multicolumn{1}{|c|}{ CRITERIA } & YES & NO & PARTLY \\
\hline 1) & $\begin{array}{l}\text { Are grammar activities taught through input processing rather than by eliciting } \\
\text { the production of the structures in isolation? }\end{array}$ & & \\
\hline 2) & $\begin{array}{l}\text { Is grammar taught by using different types of activities like input-enrichment } \\
\text { activities and structured-input activities? }\end{array}$ & & \\
\hline 3) & $\begin{array}{l}\text { Are grammar activities and exercises contextualized within the topic that is } \\
\text { being studied? }\end{array}$ & & \\
\hline
\end{tabular}

9 Based on Ellis' Second Language Acquisition Research and Language Learning-teaching

10 Criteria in this section have been designed to assess how instructions are written for the following sections in the book: The role of grammar, the teaching of reading, the teaching of writing, and the teaching of culture.

${ }_{11}$ Based on Tomlinson's Principles on Materials Evaluation and Gamboa and Sevilla's review of Combee et al.'s principles or second and foreign language testing 


\begin{tabular}{|l|l|l|l|}
\hline 4$)$ & $\begin{array}{l}\text { Do the exercises and activities reflect a real-life-like usage of the grammatical } \\
\text { structures studied? }\end{array}$ & & \\
\hline 5) & $\begin{array}{l}\text { Do the grammatical structures being taught match the students' proficiency } \\
\text { levels? }\end{array}$ & & \\
\hline 6$)$ & $\begin{array}{l}\text { Is there congruence between the grammatical structures being taught and the } \\
\text { institution's syllabus and objectives? }\end{array}$ & & \\
\hline 7) & $\begin{array}{l}\text { Are grammar rules and explanations presented logical, and in a simple, } \\
\text { understandable manner? }\end{array}$ & & \\
\hline 8) $\begin{array}{l}\text { Are grammar exercises presented sequentially and in harmony with the } \\
\text { structures studied previously? }\end{array}$ & & \\
\hline Total Points: & Degree of Compliance: \\
\hline
\end{tabular}

\section{General Observations:}

\section{THE TEACHING OF LISTENING}

INSTRUCTIONS: Check the boxes (YES/NO/ PARTLY) according to your appraisal for the textbook's compliance with each aspect inquired. Yes $=2$ points, No $=0$ points, and Partly $=1$ point.

\begin{tabular}{|l|l|l|l|}
\hline \multicolumn{1}{|c|}{ CRITERIA } & YES & NO & PARTLY \\
\hline 1) Are learners' needs reflected in the speaking tasks activities? & & & \\
\hline 2) & $\begin{array}{l}\text { Do the speaking tasks and activities reflect contextualized subject matter and } \\
\text { communicative situations? }\end{array}$ & & \\
\hline 3) Are verbal strategies considered in the speaking activities and tasks? & & & \\
\hline 4) Are verbal sources from real life used in the speaking tasks and activities? & & & \\
\hline 5) Are activities and tasks based on 'skills acquisition' principles? & & & \\
\hline Total Points: & Degree of Compliance: \\
\hline
\end{tabular}

\section{General Observations}

\section{THE TEACHING OF SPEAKING}

INSTRUCTIONS: Check the boxes (YES/NO/ PARTLY) according to your appraisal for the textbook's compliance with each aspect inquired. $Y e s=2$ points, No $=0$ points, and $P$ artly $=1$ point.

\begin{tabular}{|c|c|c|c|}
\hline CRITERIA & YES & NO & PARTLY \\
\hline Is listening presented as an active skill in the different tasks of the book? & & & \\
\hline $\begin{array}{l}\text { 2) Does the book combine different listening activities that cater to the listening } \\
\text { competencies sought to be developed in the learners? }\end{array}$ & & & \\
\hline Do the exercises and tasks offer pre-listening activities? & & & \\
\hline Do the exercises and tasks offer while-listening activities? & & & \\
\hline 5) Do the exercises and tasks offer post-listening activities? & & & \\
\hline Total Points: & \multicolumn{3}{|c|}{ Degree of Compliance: } \\
\hline
\end{tabular}

\section{General Observations}

\section{THE TEACHING OF CULTURE}

INSTRUCTIONS: Check the boxes (YES/NO/ PARTLY) according to your appraisal for the textbook's compliance with each aspect inquired. $Y e s=2$ points, $\mathbf{N o}=0$ points, and $P$ artly $=1$ point. 


\begin{tabular}{|c|c|c|c|c|}
\hline \multicolumn{2}{|r|}{ CRITERIA $^{12}$} & YES & NO & PARTLY \\
\hline 1) & $\begin{array}{l}\text { The book presents culture-oriented activities that allow students to expand their } \\
\text { view about their own and foreign cultures. }\end{array}$ & & & \\
\hline 2) & The tasks are culturally rich and promote tolerance and open-mindedness. & & & \\
\hline 3) & The tasks are non-derogatory in terms of sex, race, nationality, and ethnicity. & & & \\
\hline 4) & $\begin{array}{l}\text { The culture activities and tasks in the book are contextualized to meet the } \\
\text { students' social and cultural realities. }\end{array}$ & & & \\
\hline 5) & The activities enable learners to reflect upon their cultural reality and practices. & & & \\
\hline 6) & $\begin{array}{l}\text { The activities and tasks allow students to understand cultural practices of more } \\
\text { than just the culture of the United States and Costa Rica. }\end{array}$ & & & \\
\hline 7) & $\begin{array}{l}\text { The book presents activities and tasks that are attractive and make students } \\
\text { want to learn more about other cultures. }\end{array}$ & & & \\
\hline 8) & $\begin{array}{l}\text { The activities and tasks allow students to make critical connections between } \\
\text { what they do in the classroom and their everyday cultural reality. }\end{array}$ & & & \\
\hline \multicolumn{2}{|c|}{ Total Points: } & \multicolumn{3}{|c|}{ Degree of Compliance: } \\
\hline
\end{tabular}

\section{General Observations:}

\section{CRITICAL THINKING}

INSTRUCTIONS: Check the boxes (YES/NO/ PARTLY) according to your appraisal for the textbook's compliance with each aspect inquired. Yes $=2$ points, $N o=0$ points, and Partly $=1$ point.

\begin{tabular}{|l|l|l|l|}
\hline \multicolumn{2}{|c|}{ CRITERIA } & NO & PARTLY \\
\hline 1) & $\begin{array}{l}\text { Does the textbook allow students to make critical connections between what } \\
\text { they do in the classroom and their social and national realities? }\end{array}$ & & \\
\hline 2) $\begin{array}{l}\text { Does the test promote the use of problem-solving activities and other high-order } \\
\text { skills? }\end{array}$ & & \\
\hline 3) & $\begin{array}{l}\text { Are tasks set in a way that students can express their opinions from more than } \\
\text { just one perspective? }\end{array}$ & & \\
\hline 4) $\quad \begin{array}{l}\text { Are tasks set in a way that learners can emit value judgments in a solid, critical, } \\
\text { and logical manner? }\end{array}$ & & & \\
\hline 5) $\quad \begin{array}{l}\text { Does the textbook provide the learners with guidance on how to state critical } \\
\text { arguments both orally and in a written fashion? }\end{array}$ & & \\
\hline 6) $\begin{array}{l}\text { Does the textbook offer the bases for stating logical arguments in their pieces or } \\
\text { writing (e.g., the Toulmin Model of Argument)? }\end{array}$ & & \\
\hline Total Points: & Degree of Compliance: \\
\hline
\end{tabular}

\section{General Observations:}

\section{ASSESSMENT CONSIDERATIONS}

INSTRUCTIONS: Check the boxes (YES/NO/ PARTLY) according to your appraisal for the textbook's compliance with each aspect inquired. Yes $=2$ points, $\mathbf{N o}=0$ points, and $P$ artly $=1$ point.

12 Based on experiential teaching and on Seelye's Seven Goals of Cultural Instruction

13 Based on Sevilla and Méndez' review of principles of Critical Thinking in EFL 


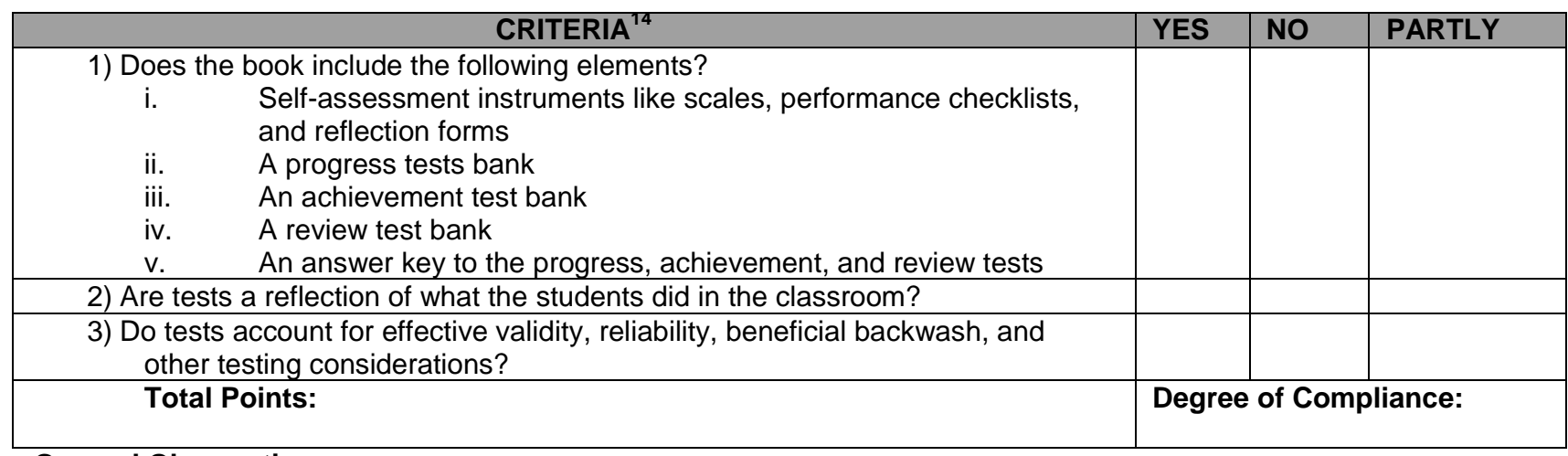

\section{General Observations:}

\section{SUPPLEMENTARY MATERIALS}

INSTRUCTIONS: Check the boxes (YES/NO/ PARTLY) according to your appraisal for the textbook's compliance with each aspect inquired. $Y e s=2$ points, $N o=0$ points, and $P$ artly $=1$ point.

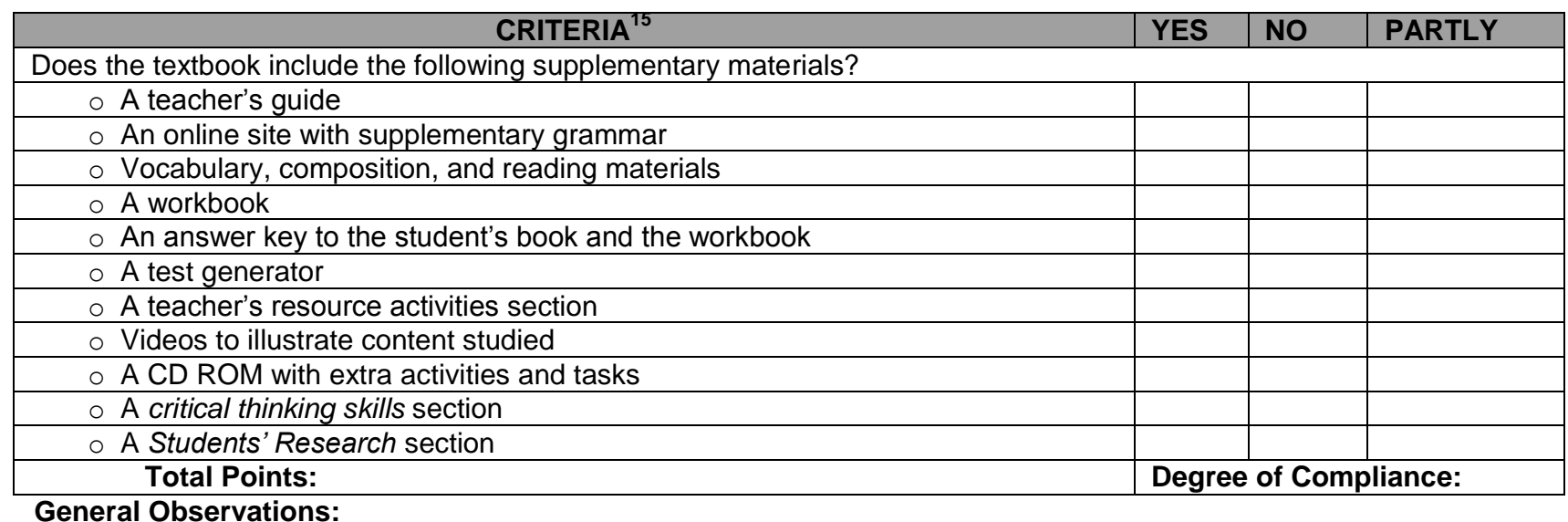

\subsection{Appendix 2: Research Validation Checklist}

\section{CRITERIA}

11) Are the instruments appropriate for measuring the intended variables?

12) Was the correct type of instrument used for data collection?

13) Is the rationale given for the selection of the instruments used?

14) Are the purpose and content of the instruments described?

15) Are the procedures for instrument validation described?

16) Do the researchers have the needed skills or experience to construct or administer the instrument?

14 Based on experiential teaching and on Coombe, Folse, and Hubley's assessment principles

15 Based on experiential teaching and McGrath's reasons for supplementation 